\title{
Effects of Cement Content, Curing Period, Gradation, and Compaction Degree on Mechanical Behavior of Cement-Stabilized Crushed Gravel Produced via Vertical Vibration Test Method
}

\author{
Yingjun Jiang $\mathbb{D}$, Tian Tian $(\mathbb{D}$, Changqing Deng $\mathbb{D}$, Kejia Yuan $\mathbb{D}$, and Yong Yi $\mathbb{1}$ \\ Key Laboratory for Special Area Highway Engineering of Ministry of Education, Chang'an University, \\ South Erhuan Middle Section, Xi'an 710064, China \\ Correspondence should be addressed to Tian Tian; 2019021033@chd.edu.cn
}

Received 23 December 2019; Revised 28 June 2020; Accepted 3 July 2020; Published 31 July 2020

Academic Editor: Emilio Bastidas-Arteaga

Copyright ( 92020 Yingjun Jiang et al. This is an open access article distributed under the Creative Commons Attribution License, which permits unrestricted use, distribution, and reproduction in any medium, provided the original work is properly cited.

In this paper, the reliability of vertical vibration test method (VVTM) was evaluated by comparing the changes in moisture content and gradation before and after forming the test piece by VVTM and static pressure method and the mechanical strength correlation between the laboratory compaction sample and the core sample in the field. The effects of cement content, curing period, gradation, and compaction degree on the unconfined compressive strength, splitting strength, and compressive rebound modulus of VVTM-compacted cement-stabilized crushed gravel (CSCG) were studied, and a mechanical strength prediction equation for VVTM-compacted CSCG was formulated. The results show that the correlation between the strength of the VVTM specimen and the field core sample can reach 92\%; the mechanical strength of CSCG will increase with increase in the cement content, and when the cement content reaches approximately $4 \%$, the increase in its mechanical strength will slow down; the mechanical strength of VVTM-compacted CSCG with different cement dosages and gradation types increased fast at 14 days of curing period and began to level off after 90 days. Compared with XM gradation, using GM gradation can improve the mechanical strength. Under different gradations and curing periods, the mechanical strength linearly increases with increase in the degree of compaction. The mechanical strength prediction equation has a high reliability; therefore, it can accurately predict the strength growth rules. Moreover, the degree of compaction increases by $1 \%$, and the mechanical strength increases by approximately $10 \%$.

\section{Introduction}

Macadam is characterized by irregular shapes and very sharp corners. It is evenly distributed in strength and basically controllable in quality. It has good adhesion to cement, asphalt, and other cementing materials. It is widely used in highway construction [1-4]. However, owing to the large consumption of road-building materials in recent years, their availability has decreased. Therefore, it is necessary to find an alternative stone resource for the construction of high-grade pavements. Moreover, researchers have used materials such as broken bricks, recycled pavement materials, recycled concrete aggregate, steel slag, and iron ore tailings [5-12].

China has abundant gravel resources. If it can be used in the construction of asphalt pavement in large quantities, it can be taken near the site during the construction of the pavement, which can not only save costs, but also reduce the disadvantages of large amounts of mineral transportation to the road and the environmental impact. However, crushed gravel has different material properties as compared with macadam. For example, compared with macadam, gravel is smooth and nonangular and has a poor bonding force with cement slurry, resulting in poor stability of the gravel base. However, cement-stabilized macadam also has severe shrinkage cracks, which are easy to separate and have low strength [13-15]. Based on this, numerous researchers have conducted related research on the road performance of cement-stabilized materials [16]. Ma et al. found that the crushed gravel processed in accordance with the required specifications can effectively reduce the crushing phenomenon during construction and has a rough and irregular 
fracture surface, which can effectively improve its adhesion to the cement slurry [17]. Lin et al. [18] and Wang et al. [19] used $6.5 \%$ overdose cement and $2 \%$ antishrinking agent and a vibration compaction method to form a cement-stabilized crushed gravel (CSCG) mixture to improve the durability of the CSCG base. Yang et al. studied the mechanical properties and durability of CSCG with rubber particles through macro- and microexperiments [20]. Mshali and Visser studied the effect of mica on the unconfined compressive strength and volume of CSCG [21]. Cheng et al. conducted indoor dry shrinkage and temperature shrinkage experiments on CSCG with different structure types and cement dosages [22]. Sun et al. studied the strength, modulus, frost resistance, water stability, and other technical properties of cement-stabilized iron ore tailings gravel in highway applications [23]. Ma et al. used reinforced mesh to enhance the carrying capacity of CSCG [17]. Han et al. conducted experimental research on the gradation and road performance of cement and fly ash-stabilized macadam based on the theory of mixture gradation [24]. Yao et al. studied the influence of cement dosage, water content, curing time, and other factors on the mechanical strength of cement-stabilized soil and put forward a prediction model of strength and rigidity of cement-stabilized soil $[25,26]$. Zhuang and Ye compared the mix design of cement-stabilized gravel powder, cement-stabilized crushed stone powder with $20 \%$ aggregate, and cement-stabilized crushed stone powder with $40 \%$ aggregate [27].

At the same time, for pavement base design and performance evaluation, the compressive strength, splitting strength, and compression modulus of resilience of CSCG are important parameters [28]. It is not economically feasible to test the mechanical properties of the drill core obtained from the road construction site. CSCG can only be tested in a laboratory under simulated conditions. Therefore, the correlation between the mechanical properties of mechanically crushed gravel samples produced in the laboratory and the field core samples is a key indicator for evaluating the quality of laboratory compaction methods [29]. In China, two laboratory compaction methods are used to produce the inorganic binder stabilized material specimens: the static pressure method (SPM) and the vertical vibration test method (VVTM). SPM is a traditional method that is widely used because of its ease of operation and economical equipment. However, the correlation between the samples formed by SPM and the core samples in the field is low; it is difficult to accurately evaluate the actual engineering properties of the basic materials and to effectively reveal the relationship between the composition and mechanical properties of the materials $[30,31]$. When detecting the on-site compaction degree, there is always a case in which the dry weight density is greater than the maximum detected compaction level, and the compaction detection degree result can be $>100 \%$. VVTM mainly simulates the vibration and oscillation of heavy rollers by vertical vibration testing equipment (VVTE), forcing solid materials to "resonate," and then small particle aggregates fill the gaps, thereby simulating the compaction effect of the roller and improving the performance of CSCG. The correlation of core samples in the field is higher $[32,33]$. Therefore, the VVTM-treated cement-stabilized macadam mixture shows better performance than SPM, and the water content and dry density obtained by VVTM are more reasonable in terms of construction quality control. Using $7 \mathrm{~d}$ unconfined compressive strength to analyze the mechanical properties, under the same cement dosage, the performance of VVTM is higher than that of SPM, which is more reasonable and effective for construction site control [18].

Although the above research has explored the road performance of CSCG, most of these studies are based on SPMforming test specimens, which are no longer compatible with the more advanced paver machinery, roller compaction machinery, and construction technology introduced in China's domestic construction, and there are limitations in the correlation between material composition and performance, leading to insufficient theoretical basis for optimizing material composition. Therefore, the reliability of VVTM was evaluated by comparing the moisture content, gradation changes of VVTM and SPM before and after molding, and the mechanical strength correlation between the sample and the core sample in the field. The influence of gradation, cement content, curing period, and compaction on the mechanical strength of CSCG was studied using VVTM. The research results can provide a reference for engineering practice.

\section{Materials and Methods}

\subsection{Raw Materials}

2.1.1. Cement. The PO 42.5 cement was produced at the Tongli Field in Queshan District, Zhumadian City, Henan Province, China. The technical specifications are provided in Table 1.

2.1.2. Aggregate. The crushed gravel obtained from Biyang, Henan Province, China, was divided into four particle sizes: $4.75-9.5,9.5-19,19-37.5 \mathrm{~mm}$, and stone chips. The technical specifications are listed in Table 2.

2.1.3. Mixtures. The aggregate gradations for CSCG with a dense skeleton type and suspended dense type are given in Table 3, and their aggregate gradation curve is depicted in Figure 1.

2.2. Test Program. In the mechanical property test, GM gradation and XM gradation are adopted, and ten kinds of mixtures with cement dosages of 3.0\%, 3.5\%, 4.0\%, $4.5 \%$, and $5.0 \%$ are, respectively, selected under the two gradations. Unconfined compressive strength, splitting strength, and compression modulus of resilience were tested, and the test curing periods were $0,3,7,14,28,60$, and 90 days.

It is noteworthy that our previous studies have found that the effect of cement content on the mechanical strength of various cement-stabilized macadam materials is similar $[32,33]$. In practice, the most commonly used cement 
TABle 1: Technical indicators of cement.

\begin{tabular}{lcccccc}
\hline Projects & Specific surface area $\left(\mathrm{m}^{2} / \mathrm{kg}\right)$ & Stability $(\mathrm{mm})$ & \multicolumn{2}{c}{ 3-day strength $(\mathrm{MPa})$} & \multicolumn{2}{c}{ Setting time $(\mathrm{min})$} \\
& & & Compressive & Flexural & Initial setting & Final setting \\
\hline Measured value & 325 & 1.5 & 35.0 & 5.4 & 295 & 440 \\
Technical requirement & $\geq 300$ & $\leq 5$ & $\geq 17.0$ & $\geq 3.5$ & $>240$ & $>360$ \\
\hline
\end{tabular}

TABLE 2: Technical indicators of the aggregate.

\begin{tabular}{|c|c|c|c|c|c|}
\hline \multirow{2}{*}{ Measured projects } & \multicolumn{4}{|c|}{ The measured results of the coarse aggregate of the following specifications } & \multirow{2}{*}{ Technical requirement } \\
\hline & $19-37.5 \mathrm{~mm}$ & $9.5-19.0 \mathrm{~mm}$ & $4.75-9.5 \mathrm{~mm}$ & Stone chips & \\
\hline Apparent density $\left(\mathrm{t} / \mathrm{m}^{3}\right)$ & 2.373 & 2.639 & 2.660 & 2.696 & $\geq 2.6$ \\
\hline Crushing value $(\%)$ & - & 19.50 & - & - & $\leq 25$ \\
\hline Needle-like content $(\%)$ & 17.60 & 29.30 & 28.20 & - & $\leq 15$ \\
\hline Sand equivalent (\%) & - & - & - & 54 & $\geq 50$ \\
\hline
\end{tabular}

TABle 3: Mineral aggregate gradation.

\begin{tabular}{lcccccc}
\hline \multirow{2}{*}{ Gradation types } & \multicolumn{4}{c}{ The mass percentage of the following sieve holes (mm) } \\
& 31.5 & 19.0 & 9.50 & 4.75 & 2.36 & 0.6 \\
\hline Skeleton dense gradation (GM) & 100 & 67.0 & 47.0 & 33.0 & 23.0 & 14.0 \\
Suspension dense gradation (XM) & 100 & 93.5 & 67.0 & 39.0 & 26.0 & 15.0 \\
\hline
\end{tabular}

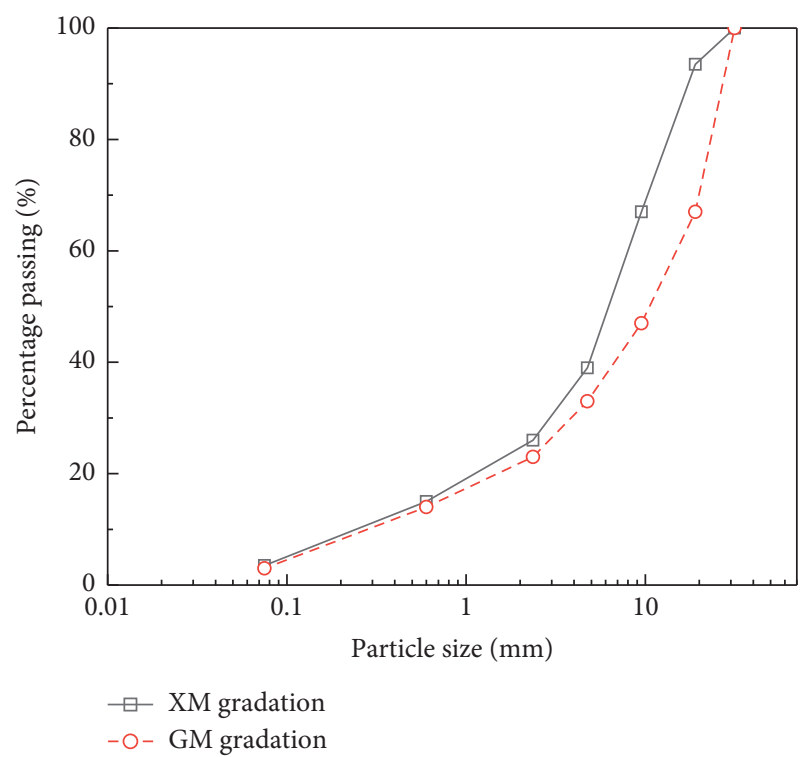

FIgURE 1: Aggregate gradation curves of CSGC.

dosage of cement-stabilized macadam base is $3.0 \%-5.0 \%$, so $3.0 \%, 3.5 \%, 4.0 \%, 4.5 \%$, and $5.0 \%$ cement dosage were selected for the CSCG.

\subsection{Testing Method}

2.3.1. Specimen Preparation. The VVTM involves the use of the vertical vibration testing equipment (VVTE) to compact the CSCG to determine the maximum dry density and the best moisture content of the CSCG and to produce the cylinder specimen with a diameter and height of $150 \mathrm{~mm}$. Figure 2 shows the schematic of VVTE [34-38]. The parameters of VVTE are as follows. The vibration frequency was $30 \pm 2 \mathrm{~Hz}$, the exciting force was $7.6 \pm 0.2 \mathrm{kN}$, the nominal amplitude was $1.4 \pm 0.2 \mathrm{~mm}$, the working weight was $3.0 \pm 0.4 \mathrm{kN}$, the weight of the upper vehicle system was $1.2 \pm 0.2 \mathrm{kN}$, and the weight of the lower vehicle system was $1.8 \pm 0.2 \mathrm{kN}$. The optimum moisture content $\left(\omega_{\text {opt }}\right)$ and maximum dry density $\left(\rho_{\mathrm{dmax}}\right)$ for the CSCG were determined via VVTE compaction, and the test time was $100 \mathrm{~s}$. We used VVTE to make cylinder specimens of the CSCG, and the testing time was $90 \mathrm{~s}$. The test steps mainly include three steps: (1) determining the $\rho_{\mathrm{dmax}}$ and $\omega_{\text {opt }} ;$ (2) forming VVTM specimens acceding to the determined $\rho_{\text {dmax }}$ and $\omega_{\text {opt }}$; and (3) curing the VVTM specimens in the curing room with a temperature of $20 \pm 2^{\circ} \mathrm{C}$ and a relative humidity of $95 \%$.

\subsubsection{Laboratory Evaluation of Mechanical Properties}

(1) Unconfined Compressive Strength. According to the test methods prescribed in the Chinese specification of JTG E51-2009 [39], to measure the unconfined compressive strength $\left(R_{c}\right)$ of CSCG specimens, the cured CSCG specimens were immersed in water for $24 \mathrm{~h}$, their $R_{c}$ was measured by an electronic universal testing machine, and the loading rate of the press is $1 \mathrm{~mm} / \mathrm{min}$.

(2) Splitting Strength. According to the test methods prescribed in the Chinese specification of JTG E51-2009 [39], to measure the splitting strength $\left(R_{i}\right)$ of CSCG specimens, the cured CSCG specimens were immersed in water for $24 \mathrm{~h}$, their $R_{i}$ was measured by an electronic universal testing machine, and the loading rate of the press is $1 \mathrm{~mm} / \mathrm{min} . R_{i}$ can be calculated according to the following equation:

$$
R_{i}=0.004178 \frac{P}{h}
$$




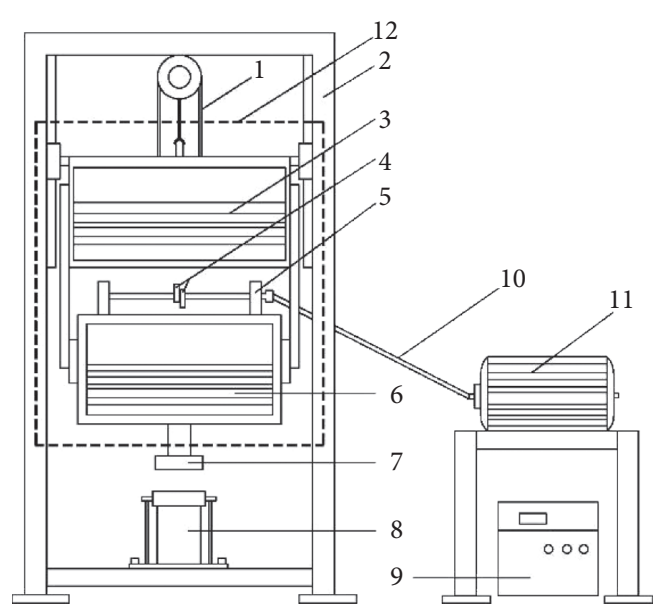

(a)

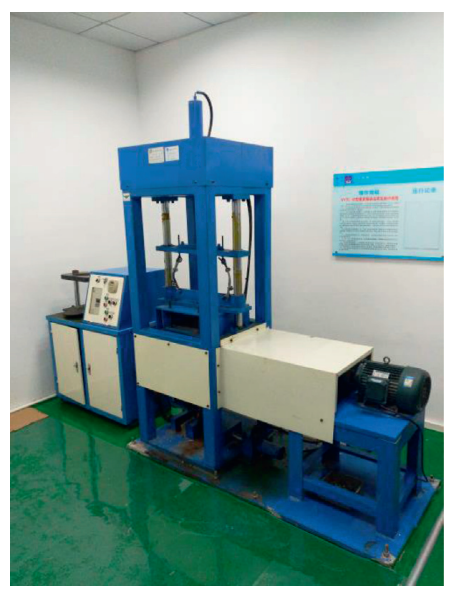

(b)

FIGURE 2: VVTE schematic: (a) diagram of VVTE: (1) lifting system; (2) frame; (3) upper system; (4) eccentric block; (5) rotation axis; (6) lower system; (7) vibratory hammer; (8) test mold; (9) control system; (10) rotation axis; (11) electric motor; (12) vibration system. (b) Photograph of VVTE in the laboratory.

where $R_{i}$ is the splitting strength, $\mathrm{MPa} ; P$ is the maximum failure load, $\mathrm{N}$; and $h$ is the height of the specimen, $\mathrm{mm}$.

(3) Compression Modulus of Resilience. According to the test methods prescribed in the Chinese specification of JTG E51-2009 [39], the compression modulus of resilience $\left(E_{c}\right)$ was measured using the top surface method, and the loading rate of the press is $1 \mathrm{~mm} / \mathrm{min}$. The rebound deformation measurement procedure is as follows: divide a predetermined unit pressure into 5 portions as the pressure value for each application. First, apply the first-level load (1/5 of the predetermined maximum load), and when the load reaches $1 \mathrm{~min}$, record the dial indicator reading and remove the load to restore the elastic deformation of time. Then, after 0.5 minutes, record the dial indicator reading, apply the second-level load (2/5 of the predetermined maximum load), and when the load reaches 1 minute, record the dial indicator reading and remove the load. Repeat the previous steps until the fifth load is completed. $E_{c}$ can be calculated according to the following equation:

$$
E_{c}=\frac{\mathrm{ph}}{l}
$$

where $E_{c}$ is the compression modulus of resilience, $\mathrm{MPa} ; p$ is the unit pressure, $\mathrm{MPa} ; h$ is the height of the specimen, $\mathrm{mm}$; and $l$ is the rebound deformation of the test piece, $\mathrm{mm}$, $l=$ reading at load - reading at unload.

\section{Reliability Evaluation for VVTM}

3.1. Changes in the Moisture Contents before and after Compaction. The changes in the moisture content of the specimens before and after they were formed using VVTM and SPM are shown in Table 4. Among them, $\omega_{\text {opt }}$ is the optimum moisture content and $\omega_{1}$ is the moisture content after forming.

Table 4 shows that the internal moisture loss rate of CSCG specimens based on SPM is approximately $12 \%$ before and after molding, while the average water content loss of VVTM-molded specimens is less than $1 \%$. The reason for this phenomenon is that the optimum moisture content before the SPM-forming specimen is determined by the heavy-duty compaction test. The water content determined using this method will be high, and the aggregate particles inside the specimen cannot be effective when the SPM is formed. The motion forms an interlocking structure. As the pressure increases, the mixed particles come closer to each other and the pores decrease, resulting in water loss in the mixture. The moisture content determined by VVTM matches well with the molding method, and the determined water content is more accurate. This indicates that the VVTM-molded test piece can better represent the true state of the CSCG material in the actual construction.

\subsection{Change in Gradation before and after Compaction.} The changes in the mineral aggregate gradation of the specimen after they were tested using the two methods are shown in Figure 3.

It can be seen from Figure 3 that in the gradation change study, although the gradation of GM and XM is adopted, the conclusion is similar; that is, VVTM has little influence on the gradation before and after the molding of the specimen and can be neglected, and the gradation changes of the specimen before and after the forming of SPM are more obvious, especially for the $9.5-19 \mathrm{~mm}$ particle size aggregate, and the crushing situation is serious. The main reason for this phenomenon is that when VVTM is used to form the specimen, the aggregate is at a more realistic optimum moisture content, so that it can move freely in the test mode and finally achieves the state of compaction and filling and the most compact state. When SPM is used to form the specimen, the moisture content of the aggregate is high, the water occupies a certain volume in the test mold, and it is difficult to be compressed. Simultaneously, the static 
TABLE 4: Changes in the moisture contents before and after compaction using two methods.

\begin{tabular}{|c|c|c|c|c|c|c|c|}
\hline \multirow[b]{2}{*}{ Test method } & \multirow[b]{2}{*}{ Cement dosage (\%) } & \multicolumn{3}{|c|}{ GM gradation } & \multicolumn{3}{|c|}{ XM gradation } \\
\hline & & $\omega_{\text {opt }}(\%)$ & $\omega_{1}(\%)$ & $\left(\omega_{\mathrm{opt}}-\omega_{1}\right) / \omega_{\mathrm{opt}}(\%)$ & $\omega_{\text {opt }}(\%)$ & $\omega_{1}(\%)$ & $\left(\omega_{\mathrm{opt}}-\omega_{1}\right) / \omega_{\mathrm{opt}}(\%)$ \\
\hline \multirow{5}{*}{ SPM } & 3.0 & 4.7 & 4.16 & 11.49 & 5.2 & 4.59 & 11.73 \\
\hline & 3.5 & 4.8 & 4.23 & 11.88 & 5.3 & 4.68 & 11.70 \\
\hline & 4.0 & 4.9 & 4.31 & 12.04 & 5.5 & 4.88 & 11.27 \\
\hline & 4.5 & 5 & 4.39 & 12.20 & 5.6 & 4.93 & 11.96 \\
\hline & 5.0 & 5.1 & 4.47 & 12.35 & 5.6 & 4.94 & 11.79 \\
\hline \multirow{5}{*}{ VVTM } & 3.0 & 3.8 & 3.77 & 0.79 & 4.2 & 4.16 & 0.95 \\
\hline & 3.5 & 3.9 & 3.87 & 0.77 & 4.4 & 4.36 & 0.91 \\
\hline & 4.0 & 4.0 & 3.97 & 0.75 & 4.6 & 4.55 & 0.87 \\
\hline & 4.5 & 4.0 & 3.96 & 1.00 & 4.6 & 4.55 & 1.09 \\
\hline & 5.0 & 4.0 & 3.95 & 1.30 & 4.7 & 4.66 & 0.85 \\
\hline
\end{tabular}

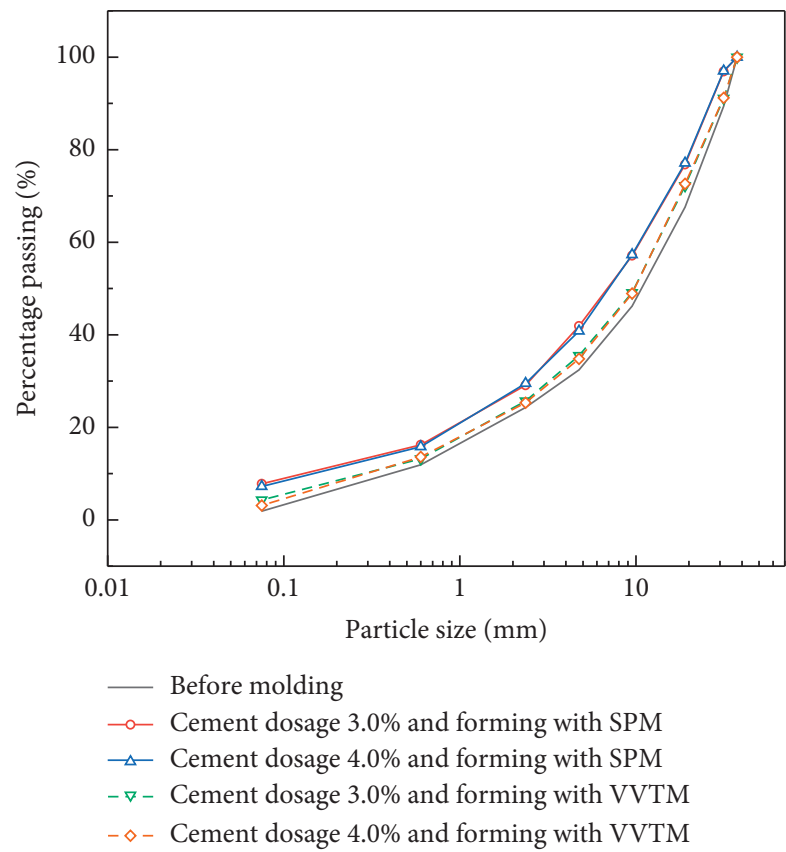

(a)

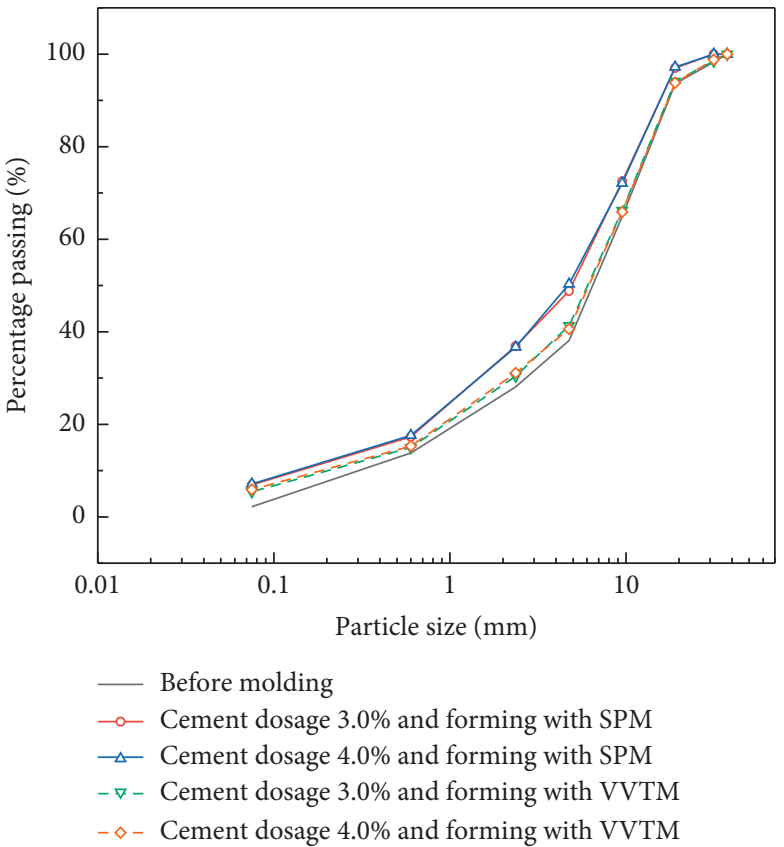

(b)

FIGURE 3: Change in gradation before and after compaction. (a) GM gradation; (b) XM gradation.

TABLE 5: Strength of field core samples and specimens formed by VVTM and SPM.

\begin{tabular}{|c|c|c|c|c|c|c|}
\hline \multirow{2}{*}{ Intensity type } & \multirow{2}{*}{ Index } & \multicolumn{4}{|c|}{ CSCG indexes for the following curing periods (days) } & \multirow{2}{*}{ Average value (\%) } \\
\hline & & 7 & 14 & 28 & 60 & \\
\hline \multirow{5}{*}{ Compressive strength } & $R_{c(v)}(\mathrm{MPa})$ & 7.0 & 8.3 & 9.6 & 10.3 & - \\
\hline & $R_{c(s)}(\mathrm{MPa})$ & 3.2 & 3.7 & 4.3 & 4.6 & - \\
\hline & $R_{c(x)}(\mathrm{MPa})$ & 7.8 & 9.1 & 10.2 & 11.4 & - \\
\hline & $R_{c(v)} / R_{c(x)}$ & 0.901 & 0.904 & 0.934 & 0.904 & 0.91 \\
\hline & $R_{c(s)} / R_{c(x)}$ & 0.410 & 0.407 & 0.422 & 0.404 & 0.41 \\
\hline \multirow{5}{*}{ Splitting strength } & $R_{i(v)}(\mathrm{MPa})$ & 0.63 & 0.75 & 0.92 & 1.05 & - \\
\hline & $R_{i(s)}(\mathrm{MPa})$ & 0.34 & 0.39 & 0.47 & 0.53 & - \\
\hline & $R_{i(x)}(\mathrm{MPa})$ & 0.69 & 0.82 & 0.98 & 1.13 & - \\
\hline & $R_{i(v)} / R_{i(x)}$ & 0.913 & 0.915 & 0.939 & 0.929 & 0.92 \\
\hline & $R_{i(s)} / R_{i(x)}$ & 0.493 & 0.476 & 0.480 & 0.469 & 0.48 \\
\hline
\end{tabular}

pressure method is applied by a constant and pressure to both ends of the mixture. In the molded specimen, the particles are not free to move, and they brush against each other before the crushing of the aggregate. It can be proved that VVTM can better ensure the composition of the material and effectively reflect its mechanical strength level. 


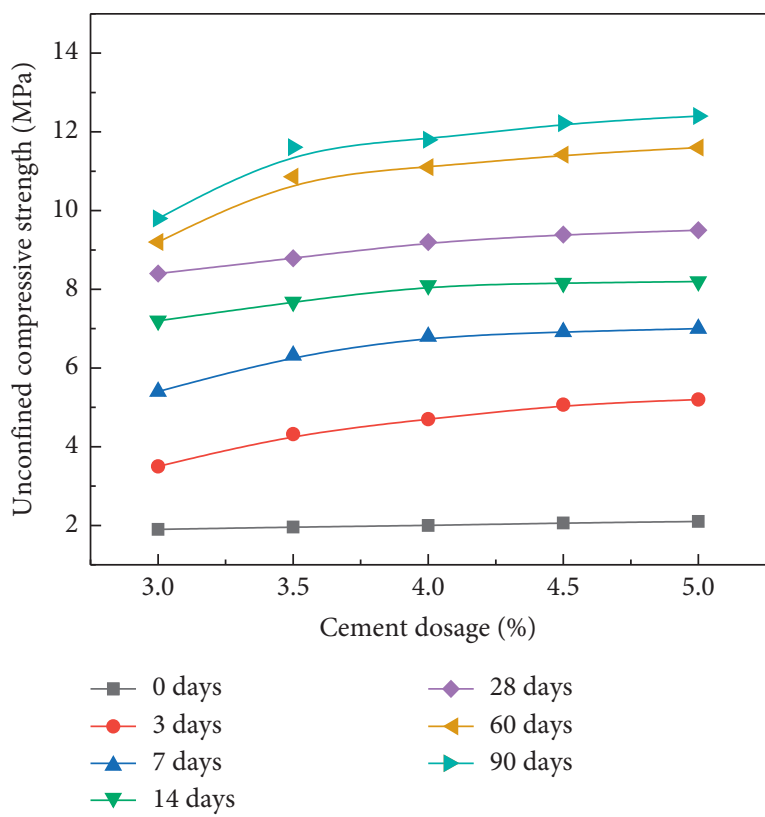

(a)

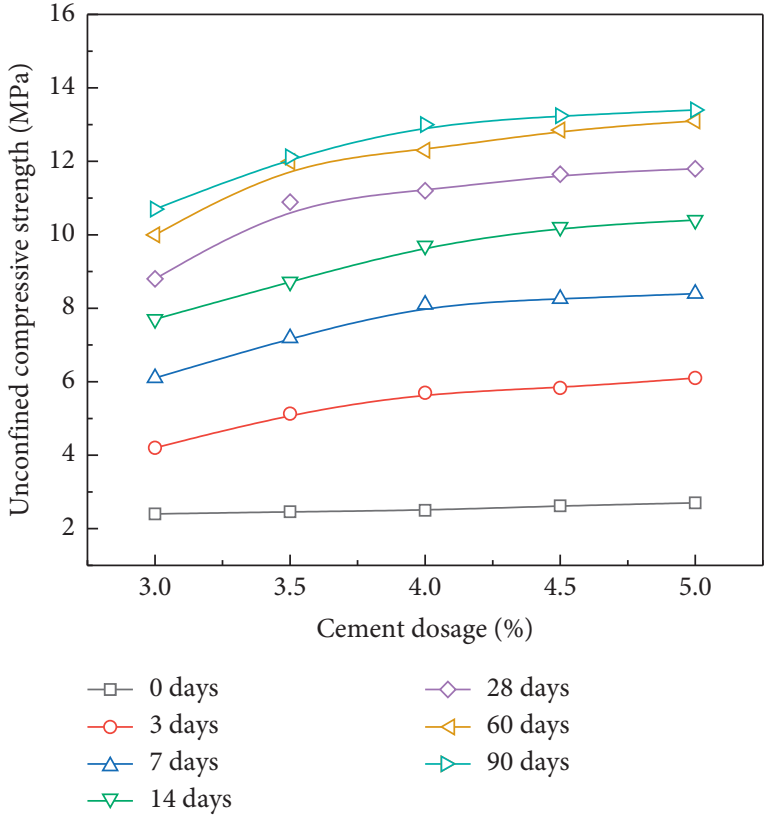

(b)

FIGURE 4: Effect of cement dosage on unconfined compressive strength. (a) GM gradation; (b) XM gradation.

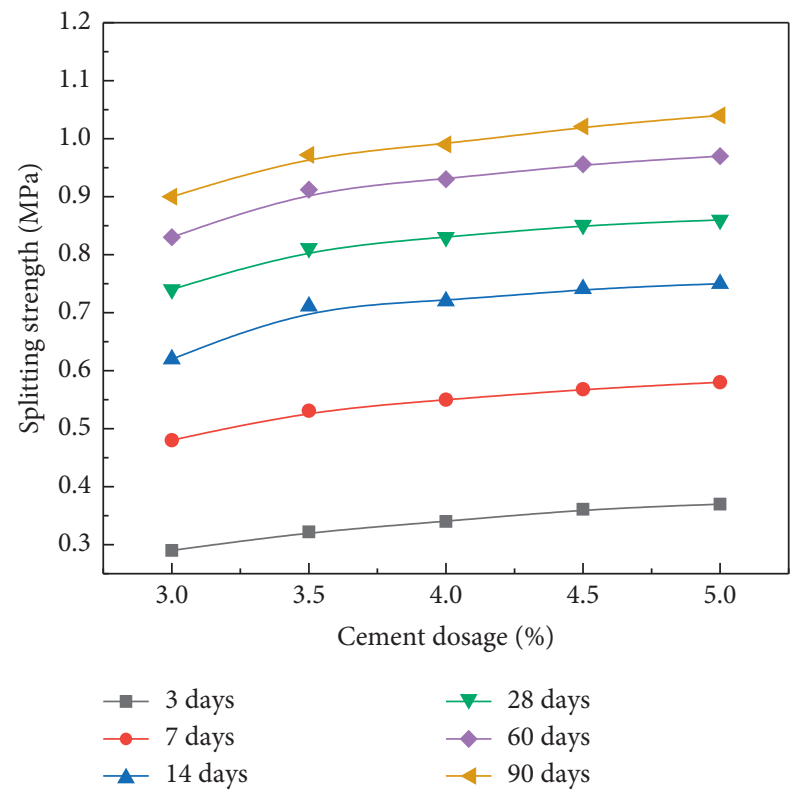

(a)

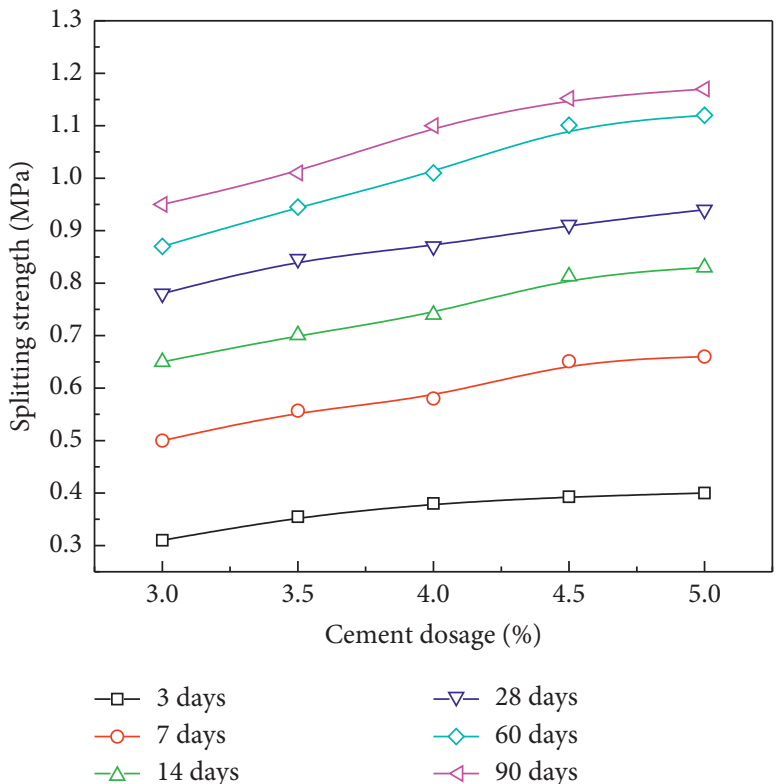

(b)

Figure 5: Effect of cement dosage on splitting strength. (a) GM gradation; (b) XM gradation.

3.3. Correlation between Field Core Samples and Specimens Formed by VVTM and SPM. The mechanical strength of the CSCG specimens prepared in the laboratory and the core samples of the physical engineering was compared. The results are given in Table 5. During the test, raw materials and mineral materials were selected considering the actual materials used in the project, and the cement dosage was $4.5 \%$. In the laboratory, VVTM and SPM were used to form test pieces, which were then placed on the construction site for curing for $7,14,28$, and 60 days. Core samples of the paving and rolling-formed base course, which were cured simultaneously and under the same conditions, were obtained by a core drilling machine. Subsequently, the indoor test piece and the on-site coring sample were moved together indoors for testing the unconfined compressive strength and splitting strength test. Among them, $R_{c(v)}$ is the 


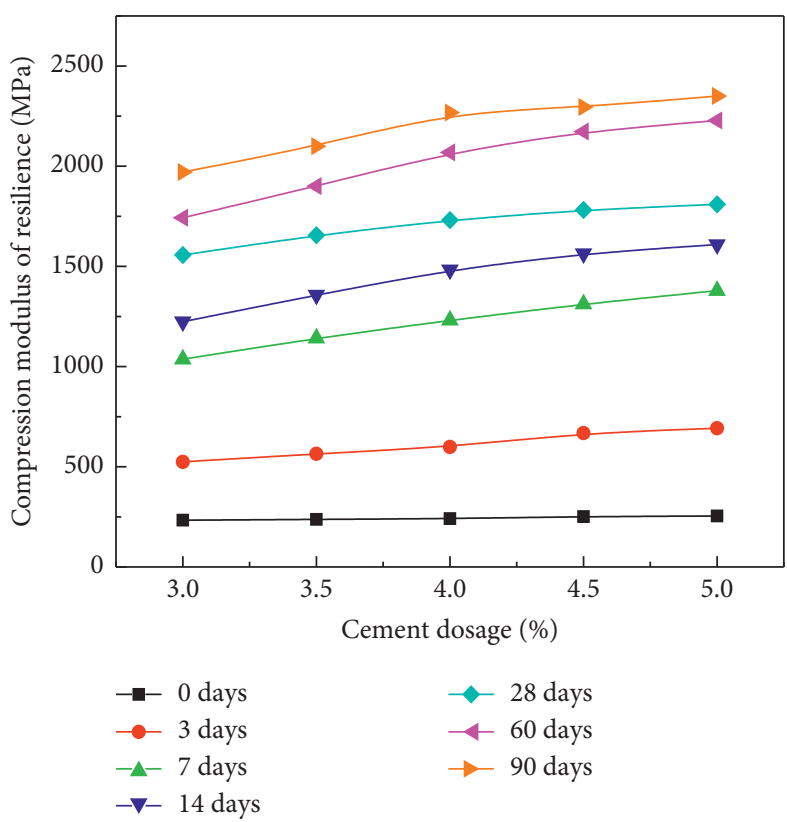

(a)

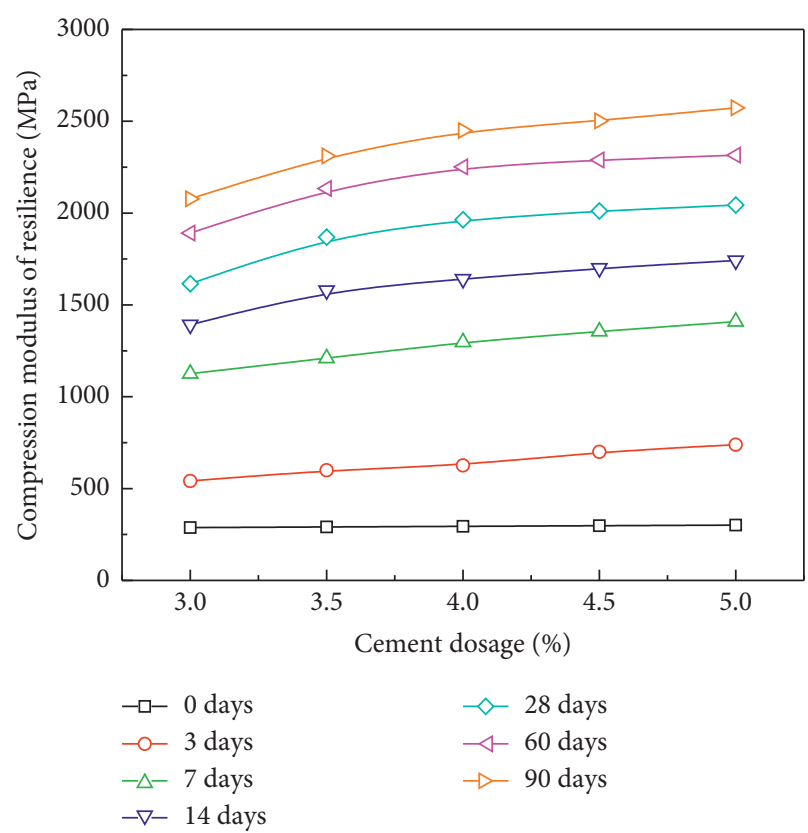

(b)

FIGURE 6: Effect of cement dosage on compression modulus of resilience. (a) GM gradation; (b) XM gradation.

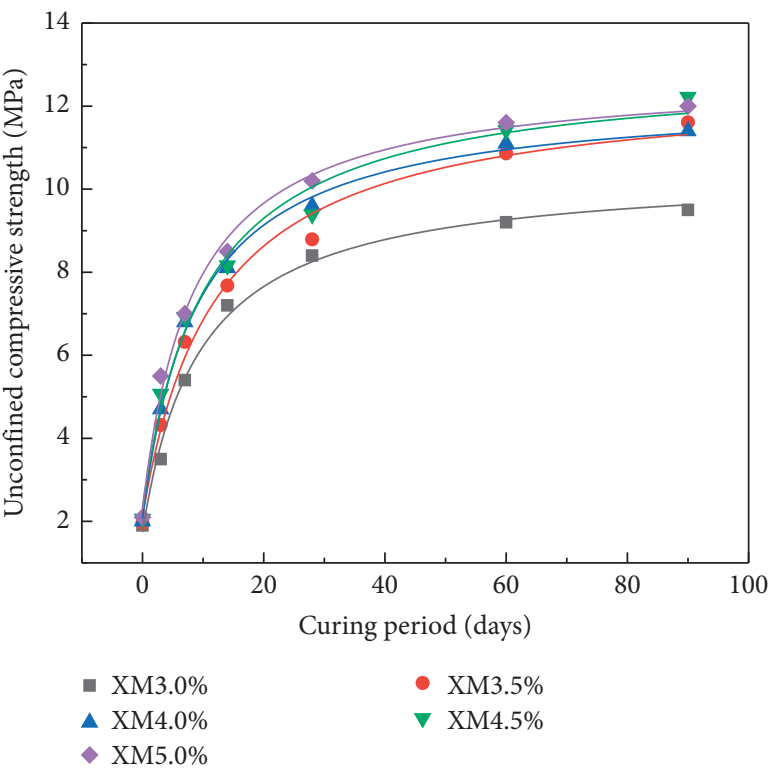

(a)

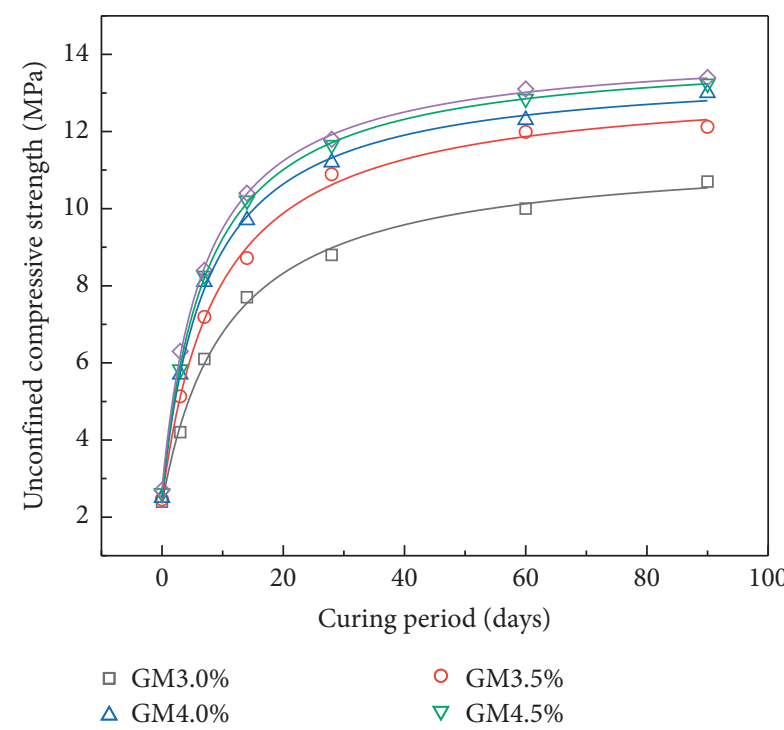

(b)

FIGURE 7: Effect of curing period on unconfined compressive strength. (a) GM gradation; (b) XM gradation.

representative value of the unconfined compressive strength of the specimen that was formed using VVTM in the laboratory, $R_{c(s)}$ is the representative value of the unconfined compressive strength of the test specimen that was formed using SPM, $R_{c(x)}$ is the representative value of the unconfined compressive strength of the core specimen that was obtained from the field, $R_{i(v)}$ is the representative value of the splitting strength of the specimen that was formed using VVTM in the laboratory, $R_{i(s)}$ is the representative value of the splitting strength of the test specimen that was formed using SPM, and $R_{i(x)}$ is the representative value of the splitting strength of the core specimen that was obtained from the field.

As shown in Table 5, the unconfined compressive strength and splitting strength of the VVTM-molded specimens were 0.91 and 0.92 times those of the on-site core samples at different curing periods, while the unconfined compressive strength and splitting strength of the SPMmolded specimens were only 0.41 and 0.48 times those of the 


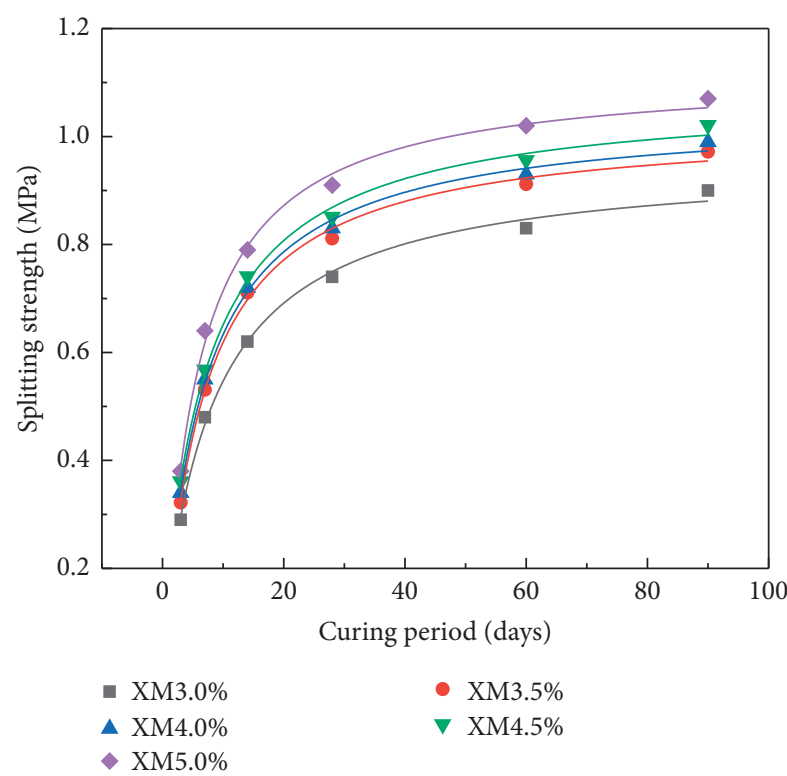

(a)

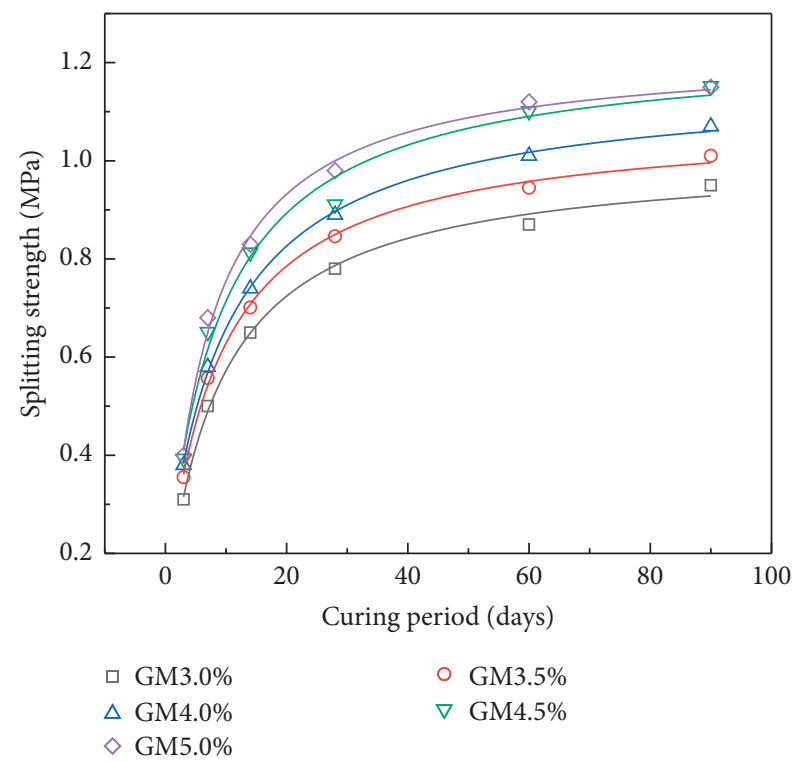

(b)

FIGURE 8: Effect of curing period on splitting strength. (a) GM gradation; (b) XM gradation.

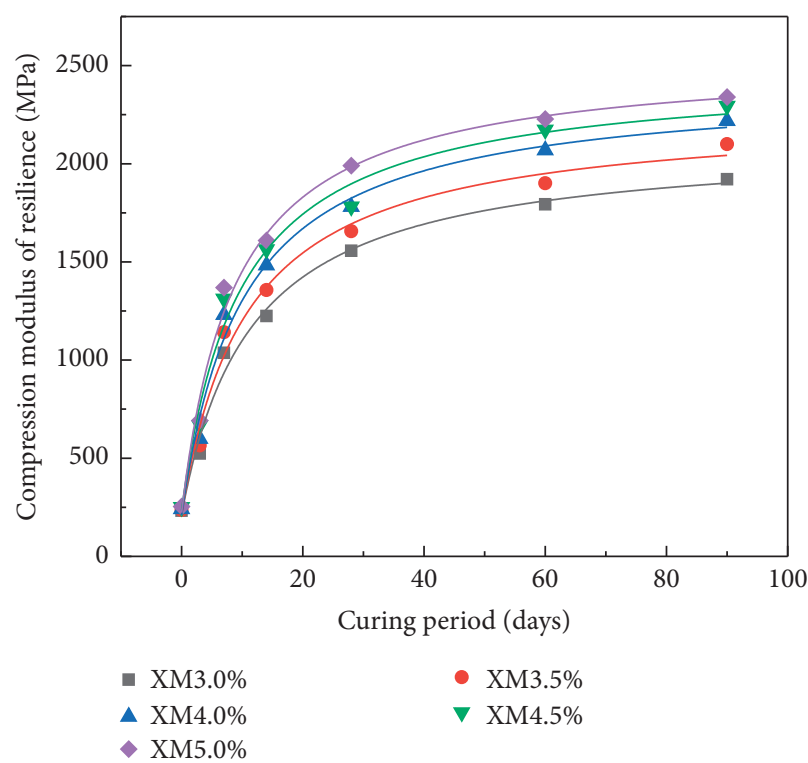

(a)

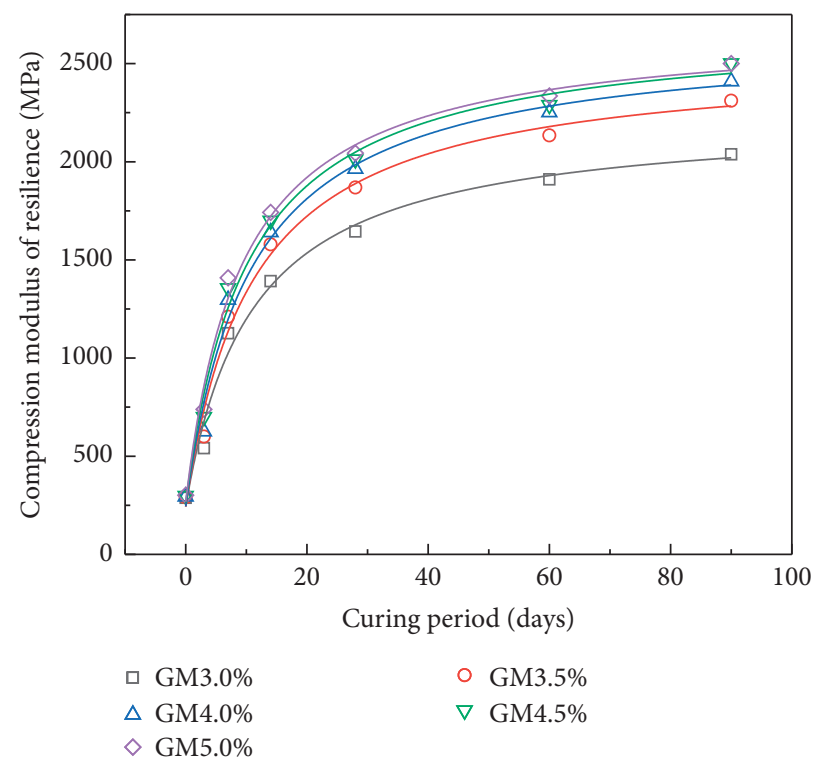

(b)

FIGURE 9: Effect of curing period on compression modulus of resilience. (a) GM gradation; (b) XM gradation.

on-site core samples. These phenomena can be attributed to the resonance of the VVTM and the resonance of the aggregate, which concentrates the relative motion between the aggregates, makes the CSCG particles more closely arranged, and the possibility of aggregate breakage is relatively small. This not only increases the density of the CSCG, but also improves its mechanical properties. However, when the test piece is formed by SPM, there is a large friction force between the aggregates, and the relative displacement is smaller than the relative displacement between the aggregates when the VVTM-molded test piece is formed. As the compaction time increases, the aggregate is easily pulverized into smaller particles, which has a negative impact on the mechanical properties of CSCG. This shows that compared with SPM, the strength of the specimen formed by VVTM is closer to the core strength of the construction site, which confirms the reliability of VVTM.

\section{Test Results and Analysis}

4.1. The Influence of the Cement Dosage. The variation of unconfined compressive strength, splitting strength, and 
TABLE 6: Parameters of growth equation of unconfined compressive strength of CSCG.

\begin{tabular}{lccccc}
\hline Gradation types & Cement dosage (\%) & $A$ & $R_{c 0}$ & $R_{c \infty}$ & $R^{2}$ \\
\hline \multirow{4}{*}{$\mathrm{XM}$} & 3.0 & 0.11 & 1.7 & 10.5 & 0.99 \\
& 3.5 & 0.08 & 2.1 & 12.6 & 0.99 \\
& 4.0 & 0.11 & 2.1 & 12.3 & 0.99 \\
& 4.5 & 0.10 & 2.3 & 12.9 & 0.98 \\
& 5.0 & 0.12 & 2.3 & 12.8 & 0.99 \\
$\mathrm{GM}$ & 3.0 & 0.09 & 2.4 & 11.5 & 0.99 \\
& 3.5 & 0.11 & 2.5 & 13.3 & 0.99 \\
& 4.0 & 0.14 & 2.5 & 13.6 & 0.99 \\
& 4.5 & 0.14 & 2.6 & 14.1 & 0.99 \\
& 5.0 & 0.14 & 2.7 & 14.2 & 0.99 \\
\hline
\end{tabular}

TABLE 7: Parameters of growth equation of splitting strength of CSCG.

\begin{tabular}{lcccc}
\hline Gradation types & Cement dosage $(\%)$ & $A$ & $R_{i \infty}$ & $R^{2}$ \\
\hline \multirow{4}{*}{$\mathrm{XM}$} & 3.0 & 0.12 & 0.96 & 0.99 \\
& 3.5 & 0.15 & 1.02 & 0.99 \\
& 4.0 & 0.14 & 1.05 & 0.99 \\
& 4.5 & 0.13 & 1.08 & 0.99 \\
& 5.0 & 0.18 & 1.12 & 0.99 \\
$\mathrm{GM}$ & 3.0 & 0.11 & 1.01 & 0.99 \\
& 3.5 & 0.11 & 1.08 & 0.99 \\
& 4.0 & 0.10 & 1.16 & 0.99 \\
& 4.5 & 0.11 & 1.23 & 0.98 \\
& 5.0 & 0.15 & 1.23 & 0.99 \\
\hline
\end{tabular}

TABLE 8: Parameters of growth equation of compression modulus of resilience of CSCG.

\begin{tabular}{lccccc}
\hline Gradation types & Cement dosage (\%) & $A$ & $E_{0}$ & $E_{\infty}$ & $R^{2}$ \\
\hline \multirow{4}{*}{$\mathrm{XM}$} & 3.0 & 0.09 & 212 & 2117 & 0.99 \\
& 3.5 & 0.09 & 216 & 2261 & 0.98 \\
& 4.0 & 0.10 & 211 & 2407 & 0.99 \\
& 4.5 & 0.10 & 234 & 2469 & 0.98 \\
& 5.0 & 0.11 & 222 & 2542 & 0.99 \\
$\mathrm{GM}$ & 3.0 & 0.09 & 245 & 2234 & 0.98 \\
& 3.5 & 0.09 & 243 & 2532 & 0.99 \\
& 4.0 & 0.09 & 245 & 2644 & 0.99 \\
& 4.5 & 0.10 & 264 & 2697 & 0.99 \\
& 5.0 & 0.11 & 268 & 2695 & 0.99 \\
\hline
\end{tabular}

TABLE 9: Ratios of compressive strengths of the CSCG in the case of GM and XM gradations.

\begin{tabular}{lccccccc}
\hline & \multicolumn{8}{c}{ Compressive strength ratio at different } \\
Cement dosage (\%) & \multicolumn{7}{c}{ curing times (days) } \\
& 0 & 3 & 7 & 14 & 28 & 60 & 90 \\
\hline 3.0 & 1.26 & 1.20 & 1.13 & 1.07 & 1.05 & 1.09 & 1.13 \\
3.5 & 1.26 & 1.19 & 1.14 & 1.14 & 1.24 & 1.10 & 1.04 \\
4.0 & 1.25 & 1.21 & 1.19 & 1.20 & 1.17 & 1.11 & 1.14 \\
4.5 & 1.27 & 1.15 & 1.19 & 1.25 & 1.24 & 1.13 & 1.08 \\
5.0 & 1.29 & 1.15 & 1.20 & 1.22 & 1.16 & 1.13 & 1.12 \\
\hline
\end{tabular}

compression modulus of resilience of CSCG with cement dosage is shown in Figures 4-6.

It can be seen from Figures 4-6 that the effects of the cement dosage of CSCG on the mechanical properties of the
TABLE 10: Ratios of splitting strengths of the CSCG in the case of GM and XM gradations.

\begin{tabular}{lcccccc}
\hline & \multicolumn{6}{c}{ Splitting strength ratio at different curing } \\
Cement dosage (\%) & \multicolumn{7}{c}{ times (days) } \\
& 3 & 7 & 14 & 28 & 60 & 90 \\
\hline 3.0 & 1.07 & 1.04 & 1.05 & 1.05 & 1.05 & 1.06 \\
3.5 & 1.10 & 1.05 & 0.99 & 1.04 & 1.04 & 1.04 \\
4.0 & 1.12 & 1.05 & 1.03 & 1.05 & 1.09 & 1.11 \\
4.5 & 1.09 & 1.15 & 1.10 & 1.07 & 1.15 & 1.13 \\
5.0 & 1.08 & 1.14 & 1.11 & 1.09 & 1.15 & 1.13 \\
\hline
\end{tabular}

TABLE 11: Resilient modulus ratio of the CSCG in the case of GM and XM gradations.

\begin{tabular}{lccccccc}
\hline & \multicolumn{8}{c}{ Resilient modulus ratio corresponding to } \\
Cement dosage (\%) & \multicolumn{6}{c}{ different curing times (days) } \\
& 0 & 3 & 7 & 14 & 28 & 60 & 90 \\
\hline 3.0 & 1.24 & 1.03 & 1.09 & 1.14 & 1.04 & 1.08 & 1.05 \\
3.5 & 1.23 & 1.06 & 1.06 & 1.16 & 1.13 & 1.12 & 1.10 \\
4.0 & 1.22 & 1.05 & 1.05 & 1.11 & 1.13 & 1.09 & 1.08 \\
4.5 & 1.19 & 1.05 & 1.03 & 1.09 & 1.13 & 1.05 & 1.09 \\
5.0 & 1.19 & 1.07 & 1.02 & 1.08 & 1.13 & 1.04 & 1.09 \\
\hline
\end{tabular}

specimens are similar in different curing periods using XM and GM gradations. The mechanical strength of CSCG will increase with increase in the cement dosage. When the cement dosage reaches approximately $4 \%$, the growth trend of its mechanical strength begins to slow down, and the effect of increasing the cement dosage on both begins to decline. This is because with the gradual increase in the cement dosage, an increasing amount of mixtures is generated by cement hydration, its own adhesion is enhanced, and it can better fill the voids in the internal framework of CSCG, making the structure dense without weak surfaces. The integrity is better, and the mechanical properties are continuously improved with increase in cement content. However, if the cement dosage is too high, CSCG is prone to shrink cracks and the strength is reduced [18]. Therefore, in practical engineering applications, a judicious amount of cement is used.

4.2. The Influence of Curing Period. The variation of unconfined compressive strength, splitting strength, and compression modulus of resilience of CSCG with curing period is shown in Figures 7-9.

It can be seen from Figures 7-9 that the mechanical strength of CSCG with different cement dosages and gradation types increases fastest at the curing period of 14 days, and the growth starts slowly after the curing period of 28 days. After the curing period exceeds 90 days, the trend of strength growth begins to flatten. It is gentle and infinitely approaches a horizontal line, and the vertical intercept corresponding to this horizontal line is the limit value of the CSCG strength. It can be seen that the early stage, especially the prehealth, must be strengthened after the grass roots are compacted.

This is because the four minerals in cement clinker, especially $3 \mathrm{CaO} \cdot \mathrm{Al}_{2} \mathrm{O}_{3}$ and $3 \mathrm{CaO} \cdot \mathrm{SiO}_{2}$, have a faster reaction 


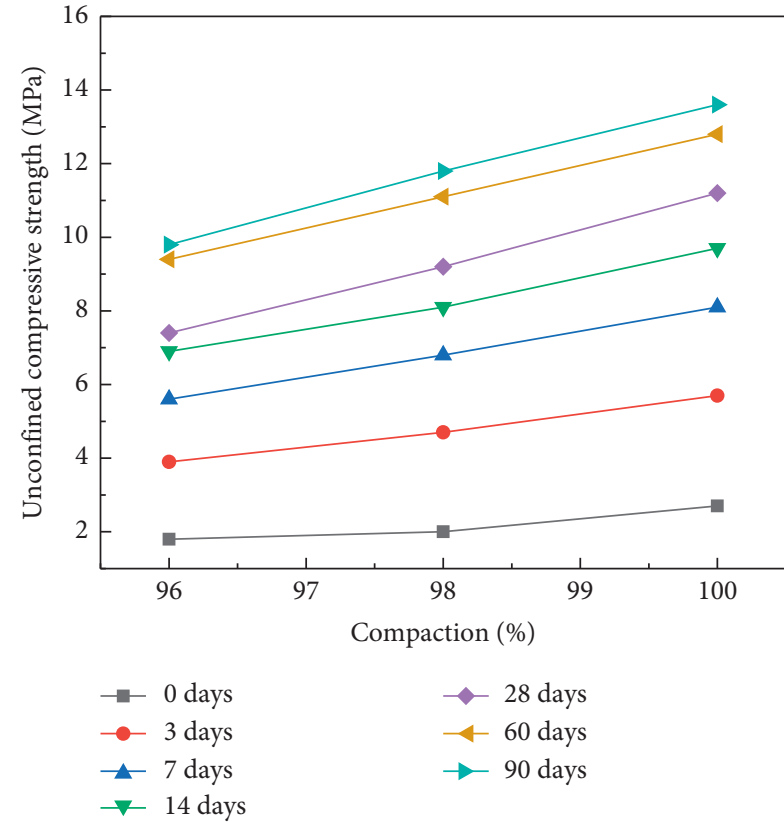

(a)

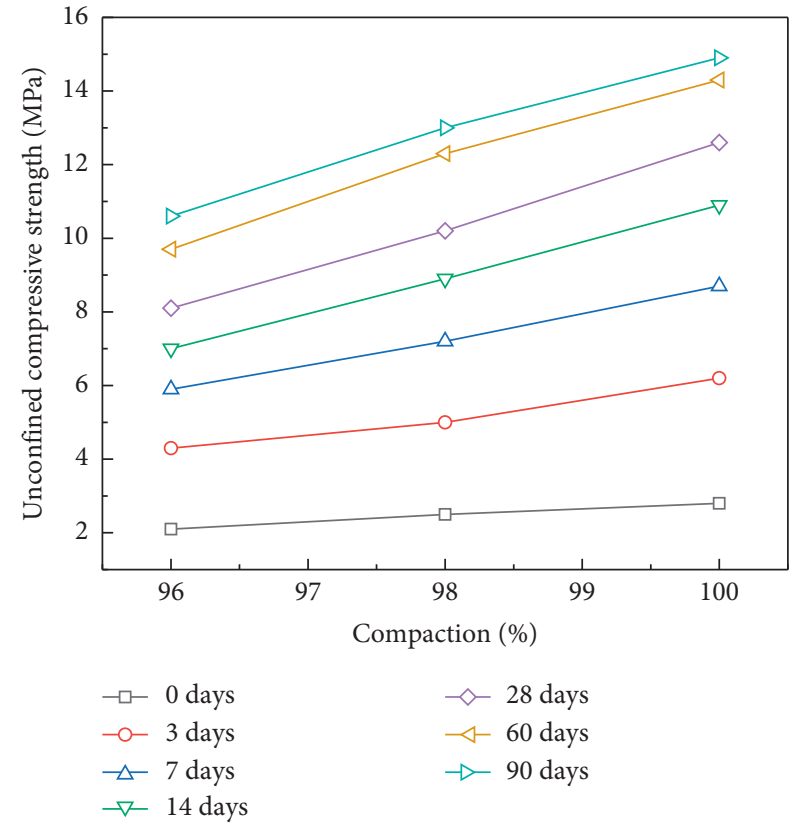

(b)

Figure 10: Effect of compaction degree on unconfined compressive strength. (a) GM gradation; (b) XM gradation.

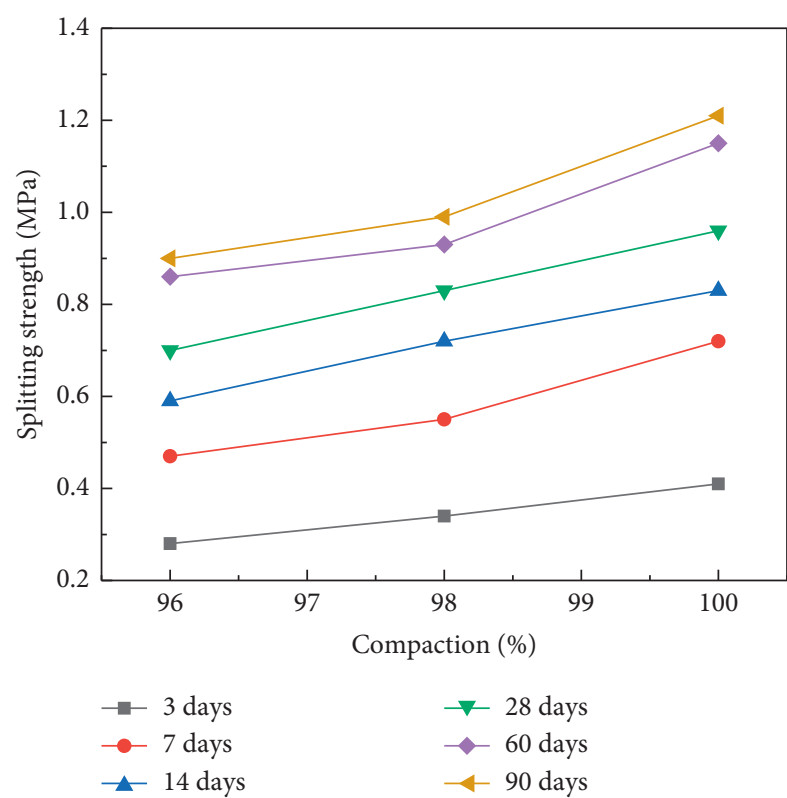

(a)

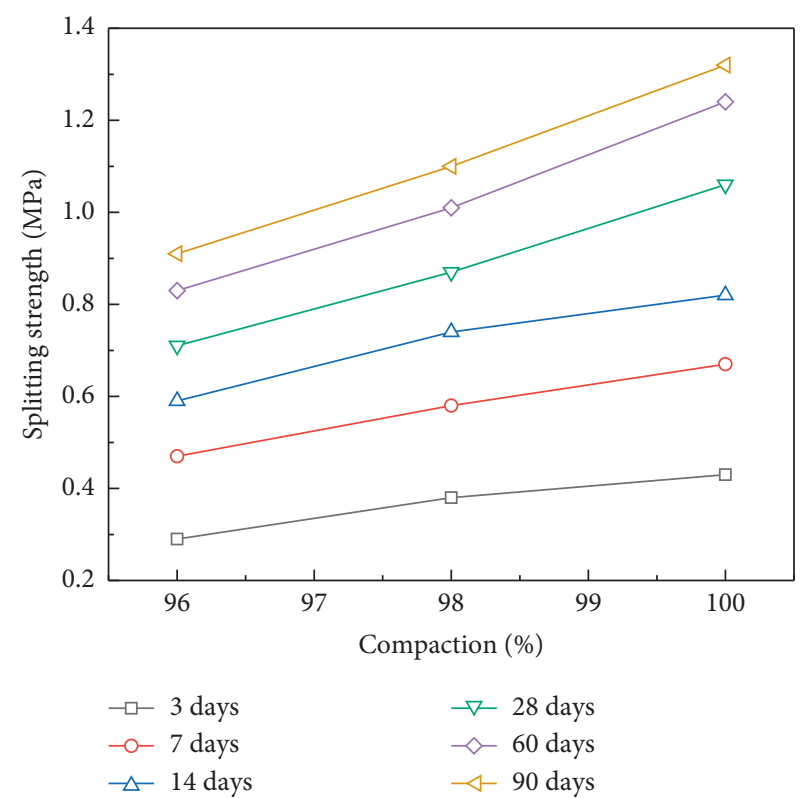

(b)

FIgURE 11: Effect of compaction degree on splitting strength. (a) GM gradation; (b) XM gradation.

rate, and $3 \mathrm{CaO} \cdot \mathrm{SiO}_{2}$ is the most important mineral component in cement; its content is generally about $40 \%$. $3 \mathrm{CaO} \cdot \mathrm{SiO}_{2}$ hydration products play a major role in early and late strength of cement. The content of $3 \mathrm{CaO} \cdot \mathrm{Al}_{2} \mathrm{O}_{3}$ is not high, but the reaction rate is the fastest. Its content determines the setting speed and heat release of the cement, which plays a certain role in the early strength of the cement. The content of $2 \mathrm{CaO} \cdot \mathrm{SiO}_{2}$ in Portland cement is about $35 \%$, its reaction rate with water is the slowest, and the heat of hydration is low. It contributes little to the early strength of cement, but it plays an important role in the later strength of cement. The content of $4 \mathrm{CaO} \cdot \mathrm{Al}_{2} \mathrm{O}_{3} \cdot \mathrm{Fe}_{2} \mathrm{O}_{3}$ is usually $10 \%$. It reacts quickly in water and has a high heat of hydration, but its strength is low and it plays an important role in resisting flexural strength. 


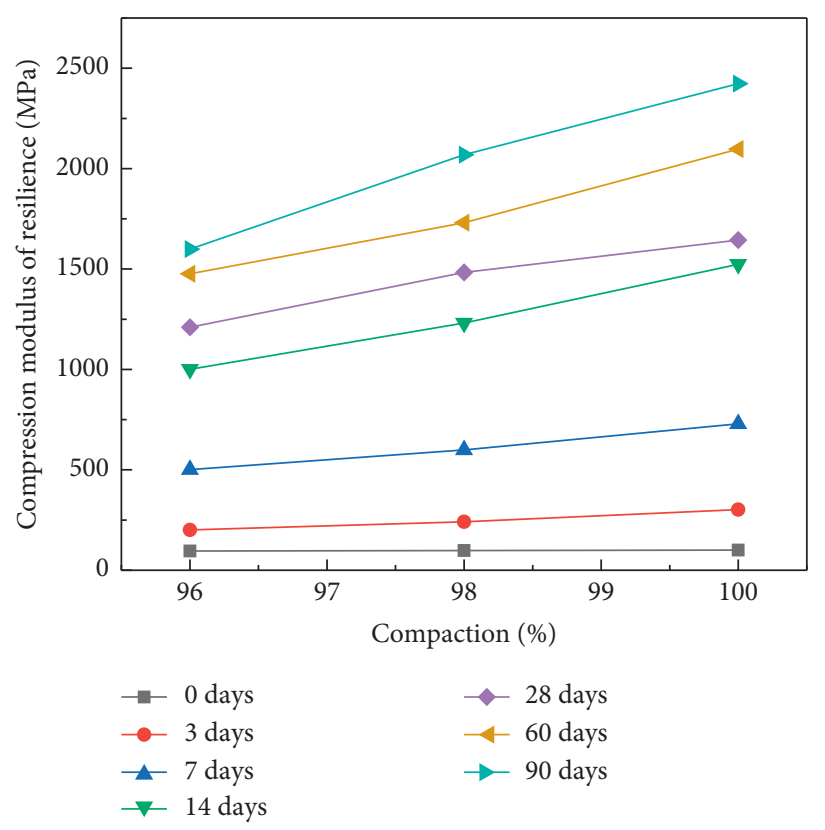

(a)

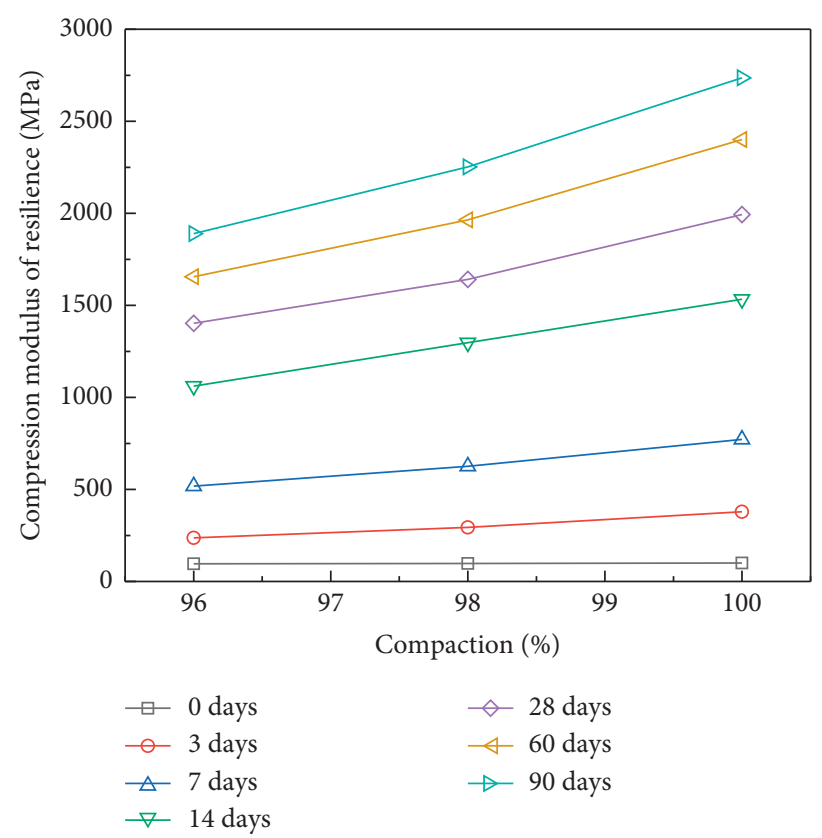

(b)

FIGURE 12: Effect of compaction degree on compression modulus of resilience. (a) GM gradation; (b) XM gradation.

We assume that CSCG has a mechanical strength growth equation which satisfies three boundary conditions as follows:

$$
\begin{array}{r}
\text { when } T=0, R=R_{0}, \\
\text { when } T=\infty, R=R_{\infty}, \\
R_{0}<R_{\infty},
\end{array}
$$

where $R$ is the strength after $T$ days of curing of CSCG, $R_{\infty}$ is the ultimate strength, $R_{0}$ is the strength after 0 days of curing of CSCG, and $T$ is the curing period of CSCG.

According to the above boundary conditions, formula (4) for the growth of the mechanical strength of the specimen can be established. From this equation, the unconfined compressive strength, splitting strength, and compressive rebound modulus of CSCG at different curing periods can be accurately predicted. At the same time, the difference is that the flexural tensile stress that the CSCG in the initial stage of molding (curing period 0 days) can withstand from the transverse direction is very small because the initial setting of the cement in the mixture has not been completed and a certain strength has not been achieved. It can be approximated that its 0 days splitting strength is zero:

$$
R=R_{\infty}-\frac{R_{\infty}-R_{0}}{A T+1}
$$

where $A$ is the regression coefficient.

Tables 6-8 show the strength growth equation parameters of CSCG under different cement dosages and gradations.

The results show that the correlation between the strength growth equation parameters of CSCG and laboratory tests is over $98 \%$, which can accurately predict the law of mechanical strength growth.

4.3. The Influence of the Gradation Types. Tables 9-11 show the unconfined compressive strength ratio, splitting strength ratio, and compressive resilient modulus ratio of GM and XM gradations.

As can be seen from Tables 9-11, compared with the XM gradation, the use of GM gradation can improve the mechanical strength, and the improvement in the early stage of health (0-28 days) is more obvious, and the strength in the later stage is not much improved. The main reason for this phenomenon is that the mechanical strength of CSCG is mainly provided by the compactness of the mixture, the arrangement of particles, and the cement hydration product, and the molding method has a great influence on the compactness of the mixture and the arrangement of the particles. VVTM improves the compactness of the mixture and optimizes the arrangement of the particles. Therefore, the mechanical strength is improved, and the influence of the gradation type on it is weakened. For the base layer, the later stage strength has more practical engineering value. From this perspective, the use of CSCG with a denser skeleton type can increase the mechanical strength by more than $4 \%$.

4.4. The Influence of Compaction Degree. The variation of the unconfined compressive strength, splitting strength, and compression modulus of resilience of CSCG with compaction degree is shown in Figures 10-12.

It can be seen from Figures 10-12 that under different gradations and curing periods, as the compaction degree 
increases, the unconfined compressive strength, splitting strength, and compression modulus of resilience of the specimens increase linearly. The degree of compaction is increased by $1 \%$, and the mechanical strength is increased by about $10 \%$. It can be seen that on-site construction improves the solidity of the base layer, which has a significant effect on improving its strength.

\section{Conclusions}

(1) The internal moisture loss rate of CSCG specimens based on SPM is approximately $12 \%$, the gradation changes significantly, and the mechanical strength of the sample is only about 0.41 times that of the core sample in the field; while the average water content loss of VVTM-molded specimens is less than 1\%, the gradation changes is small, and the mechanical strength of the sample is about 0.92 times that of the core sample on site.

(2) The mechanical strength of CSCG will increase with increase in the cement dosage. When the cement dosage reaches about $4 \%$, the growth trend of its mechanical strength begins to slow down, and the effect of increasing the cement dosage on both begins to decline.

(3) The mechanical strength of CSCG with different cement dosages and gradation types increases fastest at the curing period of 14 days, and the growth starts slowly after the curing period of 28 days. After the curing period exceeds 90 days, the trend of strength growth begins to flatten.

(4) Compared with the XM gradation, the use of GM gradation can improve the mechanical strength, and the improvement in the early stage of curing period (0-28 days) is more obvious; the strength in the later stage is not much improved.

(5) Under different grades and curing periods, the degree of compaction increases linearly with mechanical strength, the degree of compaction increases by $1 \%$, and the mechanical strength increases by about $10 \%$.

\section{Data Availability}

The data used to support the findings of this study are included within the article.

\section{Conflicts of Interest}

The authors declare that they have no conflicts of interest.

\section{Acknowledgments}

This research was supported by the scientific project from Henan Provincial Communication (Grant no. 2020J-2-2) and Scientific Research of Central Colleges of China for Chang'an University (Grant no. 300102218212). The author gratefully acknowledges the financial support as well.

\section{References}

[1] X. H. Wei and P. Zhang, "Study on fracture energy of cement stabilized aggregate," Advanced Materials Research, vol. 291-294, pp. 1141-1144, 2011.

[2] X. Ji, N. Zheng, Y. Hou, and S. Niu, "Application of asphalt mixture shear strength to evaluate pavement rutting with accelerated loading facility (ALF)," Construction and Building Materials, vol. 41, pp. 1-8, 2013.

[3] X. P. Ji and Y. J. Jiang, "Evaluation of the mechanical behaviors of cement-stabilized cold recycled mixtures produced by vertical vibration compaction method," Materials \& Structures, vol. 49, no. 6, pp. 1-14, 2015.

[4] Y. Wang, Y. Tan, M. Guo, and X. Wang, "Influence of emulsified asphalt on the mechanical property and microstructure of cement-stabilized gravel under freezing and thawing cycle conditions," Materials, vol. 10, no. 5, pp. 504-508, 2017.

[5] H. F. Wang, H. Y. Liu, and Z. R. Xiao, "Experimental study of recycled concrete aggregate for cement-stabilized macadam," Advanced Materials Research, vol. 250-253, pp. 3502-3505, 2011.

[6] S. Yan and Q. H. Zheng, "Research on the application of cement stabilized cool regeneration of the highway maintenance," Advanced Materials Research, vol. 284-286, pp. 470-474, 2011.

[7] W. Li, L. Lang, Z. Lin, Z. Wang, and F. Zhang, "Characteristics of dry shrinkage and temperature shrinkage of cement-stabilized steel slag," Construction and Building Materials, vol. 134, pp. 540-548, 2017.

[8] S. Du, "Influence of chemical additives on mixing procedures and performance properties of asphalt emulsion recycled mixture with reclaimed cement-stabilized macadam," Construction and Building Materials, vol. 118, pp. 146-154, 2016.

[9] F. Bektas, K. Wang, and H. Ceylan, "Effects of crushed clay brick aggregate on mortar durability," Construction and Building Materials, vol. 23, no. 5, pp. 1909-1914, 2009.

[10] F. Debieb and S. Kenai, "The use of coarse and fine crushed bricks as aggregate in concrete," Construction and Building Materials, vol. 22, no. 5, pp. 886-893, 2008.

[11] J. M. Khatib, "Properties of concrete incorporating fine recycled aggregate," Cement and Concrete Research, vol. 35, no. 4, pp. 763-769, 2005.

[12] V. Corinaldesi and G. Moriconi, "Behaviour of cementitious mortars containing different kinds of recycled aggregate," Construction and Building Materials, vol. 23, no. 1, pp. 289294, 2009.

[13] J. Y. Sun, S. F. Sui, and H. Q. Jiang, "Research and application of recycled concrete aggregate for cement stabilized gravel," Journal of Building Materials, vol. 11, pp. 580-584, 2008.

[14] Y. Wang, F. Ni, and W. Xuan, "Material design, construction, maintenance, and testing of pavements-research on dryshrinkage performance of cement-treated base materials," in Proceedings of the Geohunan International Conference 2009, American Society of Civil Engineers, Changsha, Hunan, China, pp. 81-86, August 2009.

[15] C. Guo, X. Cheng, and X. Zhang, "Research on the mechanical strength of emulsified asphalt-cementstabilized macadam based on neural network algorithm," The Open Civil Engineering Journal, vol. 9, no. 1, pp. 929-933, 2015.

[16] L. W. Li, "Research on the design method of cement stabilized macadam based on VTM," M.S. thesis, Chang'an University, Xi'an, China, 2011.

[17] B. Ma, W. Si, N. Li, H.-N. Wang, R.-W. Liu, and S. Adhikari, "Loading capacity strengthening to cement-stabilised crushed 
gravel using reinforced wire mesh," Road Materials and Pavement Design, vol. 15, no. 3, pp. 733-745, 2014.

[18] Y. P. Lin and J. Liu, "Test study on overdose cement stabilized crushed rock base," Advanced Materials Research, vol. 415-417, pp. 254-260, 2011.

[19] G. Wang, B. Ma, and B. Wang, "Temperature influence on shrinkage properties of cement stabilized gravel in freeze soil region," Journal of Highway and Transportation Research and Development, vol. 3, no. 2, pp. 49-53, 2008.

[20] R. C. Yang, K. Li, J. P. Zhu, S. K. Ya, and D. Zheng, "Research on the performance of the cement stabilized gravel with rubber particles," Advanced Materials Research, vol. 838-841, pp. 57-64, 2013.

[21] M. R. Mshali and A. T. Visser, "Influence of mica on unconfined compressive strength of a cement-treated weathered granite gravel," Journal of the South African Institution of Civil Engineering, vol. 54, no. 2, pp. 71-77, 2012.

[22] P. F. Cheng, X. P. Zhou, and E. C. Hou, "Experimental research about shrinkage of cement stabilized gravel base," Applied Mechanics and Materials, vol. 174-177, pp. 409-412, 2012.

[23] J. S. Sun, Y. M. Dou, Z. X. Chen, and C. F. Yang, "Experimental study on the performances of cement stabilized iron ore tailing gravel in highway application," Applied Mechanics and Materials, vol. 97-98, pp. 425-428, 2011.

[24] Y. M. Han, X. X. Shi, L. Wang, and D. M. Zhang, "Research on the capability of basal layer stabilized gravel by cement and fly-ash," Applied Mechanics and Materials, vol. 204-208, pp. 3765-3770, 2012.

[25] K. Yao, N. Li, D.-H. Chen, and W. Wang, "Generalized hyperbolic formula capturing curing period effect on strength and stiffness of cemented clay," Construction and Building Materials, vol. 199, pp. 63-71, 2019.

[26] K. Yao, Y. Pan, L. Jia, J. T. Yi, J. Hu, and C. Wu, "Strength evaluation of marine clay stabilized by cementitious binder," Marine Georesources \& Geotechnology, vol. 38, no. 6, pp. 730-743, 2019.

[27] C. Y. Zhuang and Y. L. Ye, "Pavement performance of low dosage cement stabilized gravel powder mixed with aggregates," Advanced Materials Research, vol. 668, pp. 48-52, 2013.

[28] Y. Miao, X. Chang, and S. Chen, "Analysis of factors affecting the compressive strength of cement stabilized gravel," IOP Conference Series Materials Science and Engineering, vol. 381, Article ID 012030, 2018.

[29] E. T. Selig, S. Kolias, and R. Williams, "Uniaxial tension tests on cement-stabilized granular materials," Geotechnical Testing Journal, vol. 1, no. 4, p. 190, 1978.

[30] L. Wang, X. Xie, and H. Luan, "Influence of laboratory compaction methods on shear performance of graded crushed stone," ASCE Journal of Materials in Civil Engineering, vol. 23, no. 10, pp. 1483-1489, 2011.

[31] D. Ciancio and J. Gibbings, "Experimental investigation on the compressive strength of cored and molded cement-stabilized rammed earth samples," Construction and Building Materials, vol. 28, no. 1, pp. 294-304, 2012.

[32] C. Deng, Y. Jiang, H. Lin, and X. Ji, "Mechanical-strengthgrowth law and predictive model for cement-stabilized macadam," Construction and Building Materials, vol. 215, pp. 582-594, 2019.

[33] C. Deng, Y. Jiang, T. Tian, and Z. Chen, "Resilient modulus and influencing factors of vertical vibration compacted cement-stabilized macadam," International Journal of Pavement Engineering, pp. 1-11, 2019.
[34] Y. Jiang, C. Deng, J. Xue, H. Liu, and Z. Chen, "Investigation of the fatigue properties of asphalt mixture designed using vertical vibration method," Road Materials and Pavement Design, vol. 21, no. 5, pp. 1454-1469, 2020.

[35] Y. Jiang, C. Deng, J. Xue, and Z. Chen, "Investigation into the performance of asphalt mixture designed using different methods," Construction and Building Materials, vol. 177, pp. 378-387, 2018.

[36] Y. J. Jiang, C. Q. Deng, Q. Li, and H. Liu, "Effect of compaction methods on physical and mechanical properties of asphalt mixture," Journal of Materials in Civil Engineering, vol. 31, no. 6, Article ID 04019075, 2019.

[37] C. Deng, Y. Jiang, K. Yuan, T. Tian, and Y. Yi, "Mechanical properties of vertical vibration compacted lime-fly ash-stabilized macadam material," Construction and Building Materials, vol. 251, Article ID 119089, 2020.

[38] C. Deng, Y. Jiang, H. Lin, Z. Chen, and X. Ji, "Influence of gradations on performance of emulsified asphalt cold recycled mixture produced using vertical vibration compaction method," Road Materials and Pavement Design, pp. 1-21, 2019.

[39] RIOH, Testing Methods of Material Stabilized with Inorganic Binders for Highway Engineering (JTG E51-2009), China Communications Press, Beijing, China, 2009, in Chinese. 